\title{
Activation of BKCa channels by nitric oxide prevents coronary artery endothelial dysfunction in ouabain-induced hypertensive rats
}

\author{
Ana M. Briones ${ }^{a}$, Alessandra S. Padilha ${ }^{a, c}$, Angel L. Cogolludo ${ }^{b}$, \\ Maria J. Alonso ${ }^{a}$, Dalton V. Vassallo ${ }^{c}$, Francisco Pérez-Vizcaino ${ }^{b}$ \\ and Mercedes Salaices ${ }^{a}$
}

\begin{abstract}
Objective Chronic-ouabain administration to rats induces hypertension and increases the endothelial modulation of vasoconstrictor responses. The aim of this study was to analyze whether ouabain-treatment affects the mechanisms involved in endothelium-dependent relaxation of coronary arteries.
\end{abstract}

Methods Coronary arteries from control and ouabaintreated rats $(\sim 8.0 \mu \mathrm{g} / \mathrm{day}, 5$ weeks) were used. Vascular reactivity was analyzed by isometric tension recording and membrane currents were measured using the whole-cell configuration of the patch-clamp technique.

Results In 5-hydroxytryptamine (5-HT) precontracted arteries, acetylcholine (ACh, $1 \mathrm{nmol} / \mathrm{l}-10 \mu \mathrm{mol} / \mathrm{l}$ ) induced a similar relaxant response in coronary arteries from both groups that was abolished by the nitric oxide synthase inhibitor $N^{(\mathrm{G})}$-nitro-L-arginine methyl ester $(100 \mu \mathrm{mol} / \mathrm{l})$. However, when arteries were contracted with high $\mathrm{KCl}$ $(60 \mathrm{mmol} / \mathrm{l})$ or preincubated with the large-conductance $\mathrm{Ca}^{2+}$-activated $\mathrm{K}^{+}$(BKCa) channels-blocker iberiotoxin $(0.1 \mu \mathrm{mol} / \mathrm{l})$, the relaxation elicited by ACh was more reduced in ouabain-treated than control rats. After iberiotoxin preincubation, the relaxant response of the nitric-oxide donor, DEA-NO (10 nmol/l-100 $\mu \mathrm{mol} / \mathrm{l})$ was significantly inhibited in ouabain-treated coronary arteries but not in control vessels. The soluble guanylyl cyclase activator BAY 41-2272 $(10 \mathrm{nmol} / \mathrm{l}-30 \mu \mathrm{mol} / \mathrm{l})$ induced relaxant responses that were inhibited by iberiotoxin. In coronary-artery myocytes isolated from ouabain-treated

\section{Introduction}

The $\mathrm{Na}^{+}$pump is the major cellular transport system that controls $\mathrm{Na}^{+}$homeostasis and membrane potential, both key factors in the regulation of vascular tone and blood pressure. Thus, alterations in the $\mathrm{Na}^{+}$pump could be an underlying factor in hypertension [1]. Several experimental evidences point to increased endogenous ouabain, the prototypical inhibitor of the sodium pump, or ouabainlike compounds as participating, at least in part, in the pathogenesis of hypertension [2,3]. Moreover, others and we have previously demonstrated that chronic adminis-

Part of this work was previously presented at the Experimental Biology Meeting, San Diego, California, USA, April 2008. rats DEA-NO ( $1 \mu \mathrm{mol} / \mathrm{l})$ markedly increased the amplitude of the iberiotoxin-sensitive current in the whole range of test potentials, compared with nontreated rats.

Conclusion Our results indicate that chronic ouabain treatment increases activation of BKCa currents by nitric oxide and this effect might contribute to preserve the endothelial function in coronary arteries in this hypertension model. J Hypertens 27:83-91 @ 2009 Wolters Kluwer Health | Lippincott Williams \& Wilkins.

Journal of Hypertension 2009, 27:83-91

Keywords: BKCa channels, endothelium, nitric oxide, ouabain, rat coronary arteries

Abbreviations: 4-AP, 4-aminopiridine; 5-HT, 5-hydroxytryptamine; Ach, acetylcholine; BKCa channels, large-conductance $\mathrm{Ca}^{2+}$-activated $\mathrm{K}^{+}$ channels; CASMC, coronary artery smooth muscle cells; DEA-NO, diethylamine NONOate; IBTX, iberiotoxin; KHS, Krebs-Henseleit solution; Kv channels, voltage-dependent $\mathrm{K}^{+}$channels; L-NAME, N(G)-nitro-L-arginine methyl ester; NO, nitric oxide; PSS, physiological salt solution; STOCs, spontaneous transient outward currents

${ }^{\text {a}}$ Departamento de Farmacología, Facultad de Medicina, Universidad Autónoma de Madrid, 'Departamento de Farmacología, Facultad de Medicina, Universidad Complutense de Madrid and Ciber Enfermedades Respiratorias, Madrid, Spain and ${ }^{\mathrm{C}}$ Dpto. Ciências Fisiológicas, Federal University of Espírito Santo, Vitória, Brazil

Correspondence to Dr Mercedes Salaices, Departamento de Farmacología y Terapéutica, Facultad de Medicina, Universidad Autónoma de Madrid, C/Arzobispo Morcillo 4, 28029-Madrid, Spain

Tel: +34 91 4975399; fax: +34 91 4975302; e-mail: mercedes.salaices@uam.es

Received 9 May 2008 Revised 28 July 2008

Accepted 25 August 2008

tration of exogenous ouabain induces hypertension in rats [4-9] and mice [10]. Ouabain-induced hypertension seems to be accompanied of adaptive mechanisms. In fact, increased endothelial nitric oxide-dependent modulation of vasoconstrictor responses in aorta, superior mesenteric artery and mesenteric resistance arteries has been described in this model of hypertension [7,9]. In addition, acute ouabain administration enhances basal nitric oxide release by the porcine carotid artery endothelium [11] and rat aortic endothelial cells [12].

$\mathrm{K}^{+}$channels play a key role in regulating resting arterial membrane potential and tone [13]. Activation of $\mathrm{K}^{+}$channels in vascular smooth muscle leads to hyperpolarization, 